\title{
Unusual case of laryngeal foreign body
}

\author{
S.N. Ganguly ${ }^{1}$, N.S. Reddy ${ }^{2}$, A. Shrestha ${ }^{3}$, D. Shah ${ }^{4}$, N. Shakya ${ }^{5}$, S. Acharya ${ }^{6}$ \\ ${ }^{1,2}$ Professor, ${ }^{3}$ Lecturer, ${ }^{4,5,6}$ Residents Department of ENT , College of Medical Sciences, Bharatpur, Nepal
}

\begin{abstract}
:
The foreign bodies in respiratory tract have been major cause of morbidity and present as challenge to otolaryngologist. The spectrum of presentation varies widely from sudden death due to respiratory obstruction to accidental finding during routine investigation. One case of unusual presentation of laryngeal foreign body with loss of voice is described here.
\end{abstract}

Key words: Respiratory obstruction laryngeal, foreign body,.

\section{Introduction}

Laryngeal foreign body is less common than bronchial foreign body and is potentially dangerous. The foreign bodies in respiratory tract usually occurs as an emergency. Diagnosis is made by clinical and radiological examination. The foreign body in larynx needs quick intervention. Due to delayed intervention, most of the complications including death may occur. Laryngeal impaction of foreign body is rare, as most aspirated foreign bodies pass through laryngeal inlet and get lodged down in the airway. Here we report a rare case of laryngeal foreign body presented as hoarseness of voice.

\section{Case report:}

A female patient aged 29 years, from Chirchisae Nawalparasi-8 lumbini admitted to C.M.S .T.H. Bharatpur on 27.02.09 with history of blood mixed sputum and change of voice for last 2 months. Breathlessness was also there which was felt more when

Correspondence: Dr. S.N. Ganguly

E-mail:soumen_ganguli@yahoo.co.in she lied down on supine position. She had also feeling of something moving in the throat. There was no history of trauma, fever, stridor or pain in the throat. Indirect Laryngoscopy and Nasopharyngeal laryngoscopy (Flexible) showed one thick black colour leech visible in glottic chink, which was moving. Detailed history revealed that she used to go to the forest to bring wood. She used to drink river water present in the forest which may have contained leech. During interrogation it was found that she had taken many medicines for change of voice and feeling of something moving in throat. She was taken to O.T. and direct laryngoscopy was done. An alive leech which was seen coming out of laryngeal inlet which was grasped with forceps and pulled out.. It was about $5 \mathrm{~cm}$ long and $1.5 \mathrm{~cm}$ thick. Post procedure antibiotic was given and followed up. The patient regained her voice within 2 days and had no complaints.

\section{Pathology}

Foreign body can settle in hypopharynx (5\%) larynx (2-9\%), trachea (12\%) or bronchus (83\%). The 
S.N. Ganguly et al. Unusual case of laryngeal foreign body

airway obstruction may he partial or complete. Partial obstruction occurs when the upper airways are partially occluded or obstruction is distal to carina.

Patient may present within weeks to months after foreign body aspiration. Most foreign body lodge in periphery, distal to Larynx or Trachea. However foreign body having a sharp or irregular body gets lodged in larynx or Trachea .,2

\section{Discussion}

In 1897 Gustav Killer removed a foreign body from lower respiratory Tract with a rigid bronchoscope.

During $1^{\text {st }}$ past of $20^{\text {th }}$ century Chevalier Jackson perfected endoscopic technique The incidence of foreign bodies in the airway is around $0.60 \%$ among the total foreign bodies. This is due to protection of the airway with epiglottis, arytenoid and coughing reflex. ${ }^{3}$

Foreign bodies are most common in children up to 3-4 yrs. ${ }^{1,3,4}$ The incidence is between $55-75 \%$.This is because children in that age group are curious in nature, have strong oral tendency and no molar teeth. ${ }^{1,3,4}$

Laryngeal foreign bodies as such are very rare as most inhaled objects pass into bronchus. ${ }^{5}$

Lima et $\mathrm{al}^{6}$ in a review of 91 inhaled foreign bodies, found 11 to be true glottic. 5 out of 11 had fatal outcome and transient hypoxic encephalopathy occurred in 3 patients.

Rothman et $\mathrm{al}^{2}$ found only 5 cases of laryngeal foreign bodies in a series of 225 patients. In most cases a history of choking followed by a transient cough was seen. A foreign body lodged in the larynx can cause laryngospasm and complete respiratory obstruction. ${ }^{7}$ Ambu et $\mathrm{al}^{8}$ have reported a case of one and half month neglected laryngeal foreign body in 3 years old boy. Delay in diagnosis was because there was no symptom suggestive of a foreign body in airway passage. On plain x-ray of neck a bird bone was detected. Tracheostomy was required due to granulation tissue. A Part of bone was removed by direct laryngoscopy and remaining part through tracheostomy.

Metallic foreign bodies in the larynx are rare and safety pin is commonly detected. Hussain et al ${ }^{9}$ reported a case of open safety pin in the larynx in a 6 month old boy.

Vian et $\mathrm{al}^{7}$ described the use of high frequency jet ventilation to maintain gaseous exchange in a 16 month old child who had impacted safety pin in the larynx which was removed by a tracheostomy.

Bhatt et al ${ }^{10}$ reported an unusual foreign body in the larynx in an 18 month old baby who presented with two days history of fever, refusal of feeds and stridor. History of foreign body inhalation, cough and choking was absent. Radiological investigation revealed the pathological finding. Initial diagnosis of croup was made. The child was given antibiotics, adrenaline nebulization and parenteral fluid. General condition improved but stridor (Inspiratory) persisted. ENT consultation was sought and endoscopy revealed artificial fingernail lodged between the vocal cords. Stridor improved after removal of foreign body.

Man et al ${ }^{11}$ reported an unusual case of laryngeal impaction of cervical vertebra of a toad in an infant. This was diagnosed with C.T.scan as more conventional methods failed to diagnose.

Kansara et al ${ }^{12}$ reported an unsual case of laryngeal foreign body presented with sudden loss of voice since 6 days. There was no history of trauma or fever. Indirect laryngoscopy showed shiny material attached to left cord Direct laryngoscopy was passed and with forceps the foreign body was carefully removed. 
Journal of College of Medical Sciences-Nepal, 2010, Vol. 6, No. 1

Bakshi et $\mathrm{al}^{13}$ reported two interesting cases in which the diagnosis of foreign body in the larynx was not suspected preoperatively. A three and half year old female child was diagnosed as a case of bronchitis and was later found to have a metallic spring in the supraglottic region which was removed by direct laryngoscopy under general anesthesia. The other patient, a 32-year-old male, was diagnosed to have a fibrous lesion in the larynx one year previously, and on laryngoscopy a vegetable, speculated foreign body was found after excising the fibrous lesion on the left false cord. Both the cases are symptom free 18 months after endoscopy.

\section{Conclusion}

Unusual foreign body like the case which we reported may miss the diagnosis as there was no history of respiratory symptom. Moreover, the foreign body was radiolucent. Complete detailed history helps to detect such case. It is important to diagnose the case as early as possible, so that there may not be any catastrophe.

\section{Acknowledgement}

We are thankful to the superintendent of C.M.S-T.H, Bharatpur, Nepal for publication of this article.

\section{Fig-1}

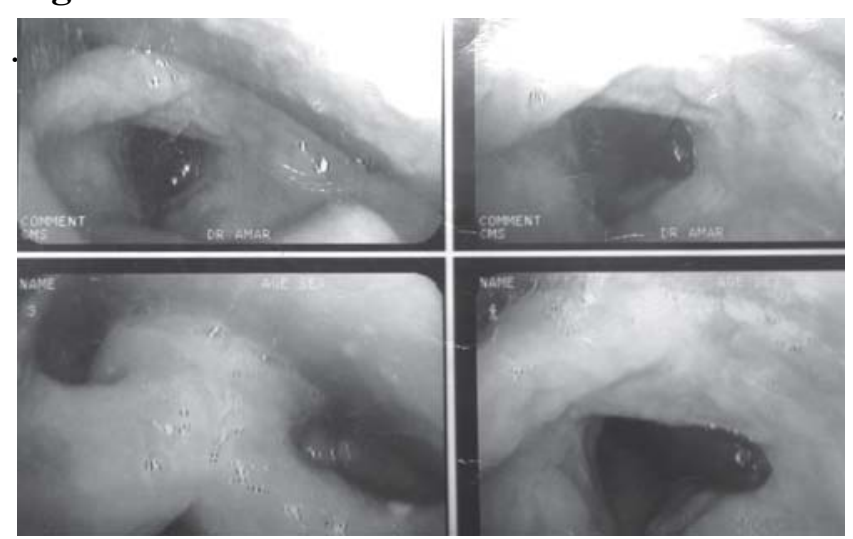

Black colour Leech visible in the glottis.

\section{References:}

1. Diop EM, Tall A, Diout $R$. Laryngeal foreign body: Management in children in Senegal: Arch pediatric. 2000;7:10-5.

2. Rothman BF, Beockman CR. Foreign bodies in the larynx and tracheobronchial tree in children: A review of 225 cases. Ann Otol Rhinol and Laryngol 1980; 89:434-6

3. Ricardo RF, Walter SM. Foreign body aspiration through tracheotomy. Brazilian Journal of Otorhinolaryngology 2005;71: 234-6.

4. Ellan M. Tracheo-bronchical foreign bodies. Otolaryngologic clinics of North America 2000;33:17-8.

5. Kent SE, Watson MG. Laryngeal foreign bodies. Journal of Laryngology and Otology 1990;104:131-3

6. Lima JA. Laryngeal foreign bodies in children: a persistent life threatening problem. Laryngoscope 1989;99:415-20

7. Vain SS, Dhara SS, Sim CK. Removal of foreign body using high frequency jet ventilation. Anaesthesia 1991;46:741-3

8. Ambu VK, Narayanan P, Rathnasingam V. Neglected laryngeal foreign body. The Journal of Laryngology and Otology 2001; 115:740-2

9. Hussain SS, Raine CH, Caldicott LD et al. An open safety pin in the larynx: case report. The Journal of Laryngology and Otology 1994;108:254-5

10. Bhat NA, Oates $J$. An unusual foreign body in the larynx: a case report. The journal of Layrngoloy \& Otology 1996;110:1164-5

11. Man DW, Engzell UC, Hadgis C et al. An unusual laryngeal foreign body. In an infant J Otolaryngol 1986; 115: 127-9

12. Kansara AH ,Shah HV, Patel MA et al. Unusual case of Laryngeal Foreign body Indian Journal of Otolaryngology and Head and Neck Surgery2007;59: 63-5.

13. Jasmanti Bakshi, Mann SBS,Gupta AK. Unusual presentation of laryngeal foreign bodies - report of two rare cases. Indian Journal of Otolaryngology and Head and Neck Surgery 2007;59:252-4. 